\title{
The Contingent Negative Variation in Remitted Paediatric Bipolar Patients: No Evidence of Abnormality
}

\author{
Nandini Banerjee ${ }^{1}$, Vinod K. Sinha ${ }^{1}$, Meera Jayaswal ${ }^{2}$ and Pushpal Desarkar ${ }^{3 凶}$ \\ ${ }^{1}$ Central Institute of Psychiatry, Jharkhand, India \\ ${ }^{2}$ Department of Psychology, Ranchi University, Jharkhand, India \\ ${ }^{3}$ Centre for Addiction and Mental Health, Department of Psychiatry, University of Toronto, Toronto, Canada
}

\begin{abstract}
Although the Contingent Negative Variation (CNV) paradigm has been useful in schizophrenia, limited research involving such paradigm in subjects with Bipolar Disorder (BD) has produced contradictory findings. To the best of our knowledge, no study has investigated CNV in Paediatric Bipolar Disorder (PBD) subjects. Thirty remitted PBD patients and thirty matched healthy control group subjects participated in the study. No significant between group main effect could be found for either CNV latency or amplitude. We propose that $\mathrm{CNV}$ is unlikely to be a true endophenotype of BD. However, absence of $\mathrm{CNV}$ finding during euthymic phase in BD may help us in advancing our understanding of $\mathrm{BD}$ and such finding may, in fact, have some specificity with regard to differentiating BD from schizophrenia.
\end{abstract}

Psychiatry Investig 2013;10:196-199

Key Words Child, Adolescent, Bipolar disorder; Contingent negative variation.

\section{INTRODUCTION}

Contingent Negative Variation (CNV), first reported by Grey Walter, ${ }^{1}$ consists of slow surface negativity that mostly peaks at central brain locations. CNV is typically studied using the S1-S2 paradigm in which the first stimulus (S1) serves as a preparatory signal for an "imperative" stimulus (S2), to which a motor response is made. CNV, although believed to reveal motor preparation, has also been found to reflect non-motoric processes. In fact, studies done in the past suggested that $\mathrm{CNV}$ may be a sensitive indicator of attention and arousal process$\mathrm{es}^{2,3}$ particularly focused attention ${ }^{4}$ and sustained attention, ${ }^{5}$ stimulus anticipation and visuo-spatial working memory. ${ }^{6,7}$

Adult subjects with Bipolar Disorder (BD) have been consistently found to have cognitive deficits in the form of verbal memory, sustained attention ${ }^{8,9}$ even during the euthymic phase. Such deficits have also been found to be one of the core deficits in Paediatric Bipolar Disorder (PBD) patients. ${ }^{10-12}$ Rese-

Received: May 11, 2012 Revised: September 13, 2012

Accepted: December 5, 2012 Available online: May 30, 2013

$\triangle$ Correspondence: Pushpal Desarkar, MD, DPM

Centre for Addiction and Mental Health, Department of Psychiatry, University of Toronto, 1001 Queen Street West, Toronto, ON M6J 1H4 Canada

Tel: +1-416- 535-8501, ext. 2726, Fax: +1-416-583-1268

E-mail: pushpal.desarkar@utoronto.ca

(a) This is an Open Access article distributed under the terms of the Creative Commons Attribution Non-Commercial License (http://creativecommons.org/licenses/bync/3.0) which permits unrestricted non-commercial use, distribution, and reproduction in any medium, provided the original work is properly cited. arch over the decades have established Event Related Potentials as one of the main tools available for investigating the function of the human brain considering their high level of sensitivity to cognitive processing like attention and memory processes. In fact, CNV is an established paradigm to study cognitive processes in schizophrenia and a number of studies have consistently reported reduced CNV in this condition. ${ }^{13-15}$ However, limited research involving CNV paradigm in subjects with BD has produced contradictory findings.

In an early study, Rizzo et al. ${ }^{16}$ recorded CNV in five adult subjects with bipolar cyclothymic psychosis in the different phases of illness and under normal clinical conditions and reported an average voltage decrease in the depressive phases and a more conspicuous decrease in the manic phases. However, a later study by Ghadirian and Dubrovski ${ }^{17}$ that almost followed a similar design concluded that CNV parameters 'cannot be used as markers of the mental state in bipolar patients nor do they reflect specific drug effect.' The authors recorded CNV and mood changes as well as medications in six BD patients over a period of eight months and did not find any relationship between CNV parameters and clinical variables.

We observed that both the studies were done on a limited number of subjects. The question whether brains of BD patients would show abnormal information processing indexed by CNV when compared with the healthy control population is still unanswered. To the best of our knowledge, we are not 
aware of any ERP study that has used CNV paradigm in PBD subjects. Our group investigated the presence or absence of cognitive deficits in a pure sample of PBD subjects during full remission using a battery of neuropsychological and electrophysiological tools and one of our additional objectives was to investigate CNV parameters in remitted PBD subjects, in comparison to matched healthy controls. This work was mainly exploratory; therefore, we tested null hypothesis.

\section{METHODS}

\section{Subjects}

21 boys and 9 girls $(\mathrm{n}=30)$ with the DSM-IV ${ }^{18}$ diagnosis of bipolar disorder or manic episode (single episode) and age-, sex-, full scale IQ and handedness-matched 30 normal healthy (no score on the 5-item General Health Questionnaire $-5^{19}$ ) controls (21 boys, 9 girls) were included in the current study. Kiddie Schedule for Affective Disorders and Schizophrenia-Present and Lifetime Version (K-SADS-PL) ${ }^{20}$ was used to diagnose PBD subjects and exclude comorbidities. PBD subjects were recruited if, at the point of intake, had been symptom free (Young Mania Rating Scale ${ }^{21}<6$; Hamilton Depression Rating Scale ${ }^{22}$ $<7)$ for at least 2 months. The study was carried out at Central Institute of Psychiatry; Ranchi, India and PBD subjects were recruited from the outpatient department of the division of child and adolescent psychiatry. Informed consent was obtained from parents and guardians. The study had already obtained approval of the Institute Ethics Committee.

\section{CNV data acquisition}

All subjects were asked not to smoke or take caffeine three hours prior to the recording. The participants were explained the procedures before beginning the experiment. The recording was carried out in a sound- and light-attenuated air conditioned room (average room temperature 18 degree $\mathrm{C}$ ) with participants being seated comfortably in a chair with eyes closed but alert condition. The recording was done between 9.00 a.m. and $3.00 \mathrm{p} . \mathrm{m}$. and at the time of recording no participant had fever or fasting for more than 2-3 hours.

CNV data acquisition was done with Neuropack Sigma 8 (Nihon Kohden, Japan) through silver chloride disk electrodes positioned according to 10/20 electrode placement system. The electrode impedance was kept below $5000 \mathrm{ohm}$. The linked ear-lobe electrodes were used as the reference and the EOG was recorded from a separate electrode which was placed over FP1 site.

Subjects were provided with the warning stimulus (S1), which consisted of an auditory stimulus provided through a head phone bilaterally. The intensity of the auditory stimulus was 75 $\mathrm{dB}$; tone frequency was $1.5 \mathrm{kHz}$ with a plateau time of 30 mil- liseconds. The warning stimulus was followed by an imperative stimulus (S2), which consisted of repetitive flashes of red light being provided through a goggle. The interval between the alerting and the imperative stimulus was set at 2 seconds. The subjects were instructed to press a switch as soon as the repetitive stimuli were given with their preferred hand which terminated the imperative stimuli. (S2). The circuit was so arranged that it was ineffective if pressed before the onset of the imperative stimuli. The preset count was 100 and paper speed was $25 \mathrm{~mm} /$ second.

The EEG was recorded from 7 electrode positions as per the international 10/20 system (Fz, Pz, Cz, C4, C3, F3, F4). Each electrode was referred to linked ear reference electrode. For $\mathrm{CNV}$ recording, a band pass filter was applied with range being 0.01-20 HZ. All signals were recorded for 3 seconds; 500 milliseconds before S1 to 500 milliseconds after S2. The online automated artifact rejection based on an amplitude window, with rejection of trials with amplitude $\pm 100 \mu$ v, was used in this study. To improve the accuracy of artifact rejection, record was also visually inspected by two authors.

In the present study, the late CNV was included in the analysis and the wave was marked only at the maximum point of negativity immediately before the occurrence of $\mathrm{S} 2$.

\section{Statistical analysis}

Group differences for sample characteristics were examined with independent $t$-test and chi-square test wherever applicable. In order to avoid multiple comparison and related type I error and also to minimize the confounding effect of age, a multivariate general linear model was devised with group (patient vs control) as between subject factors, CNV measures as dependent variables and age as covariate. Pillai's trace statistic was used to interpret all multivariate general linear modeling statistics. Statistical analysis was done using Statistical Package for Social Sciences [SPSS ver. 11.0]. In this study, a level of significance ( $\alpha$ ) of $<0.05$ (two tailed) was taken to consider a result (either a group difference or correlation) statistically significant.

\section{RESULTS}

As matched control group was taken, there was no significant difference in terms of age $(\mathrm{p}=0.841), \operatorname{sex}(\mathrm{p}=1.000)$ and full scale IQ ( $\mathrm{p}=0.115)$. Mean age of onset in the PBD group was 13.73 years $(\mathrm{SD}=1.36)$ and mean duration of illness (months) was 13.33 months ( $\mathrm{SD}=8.74$ ). In the $\mathrm{PBD}$ patients, mean number of depressive and manic episodes was $0.33(\mathrm{SD}=$ $0.66)$ and $1.3(\mathrm{SD}=0.65)$ respectively. The patient group had spent an average of 1.06 months $(\mathrm{SD}=4.37)$ in depressed phase and $3.93(\mathrm{SD}=2.44)$ months in manic phase while remaining symptomatic. Ten out of 30 patients had a history of psy- 
Table 1. General linear model-multivariate test of between subject (patient group vs. control group) Omnibus effects for contingent negative variation (CNV) amplitude \& latency

\begin{tabular}{|c|c|c|c|c|}
\hline $\mathrm{CNV}$ & Patients $($ Mean $\pm \mathrm{SD})(\mathrm{N}=30)$ & Normal control $($ Mean $\pm S D)(N=30)$ & Pillai's Trace & $\mathrm{p}$ \\
\hline N1 latency (ms) & & & 0.111 & 0.622 \\
\hline $\mathrm{Fz}$ & $1901.33 \pm 33.39$ & $1910.66 \pm 37.59$ & & \\
\hline $\mathrm{Cz}$ & $1902.00 \pm 33.36$ & $1908.00 \pm 38.98$ & & \\
\hline $\mathrm{Pz}$ & $1902.00 \pm 31.99$ & $1908.00 \pm 38.18$ & & \\
\hline $\mathrm{C} 3$ & $1898.33 \pm 28.29$ & $1909.66 \pm 38.19$ & & \\
\hline $\mathrm{C} 4$ & $1904.33 \pm 28.12$ & $1910.33 \pm 39.34$ & & \\
\hline Fp1 & $1899.00 \pm 33.25$ & $1907.00 \pm 39.57$ & & \\
\hline F3 & $1900.00 \pm 32.69$ & $1907.33 \pm 37.22$ & & \\
\hline $\mathrm{F} 4$ & $1902.66 \pm 33.00$ & $1911.00 \pm 37.63$ & & \\
\hline N1 amplitude $(\mu \mathrm{V})$ & & & 0.211 & 0.128 \\
\hline $\mathrm{Fz}$ & $9.72 \pm 9.04$ & $11.29 \pm 8.25$ & & \\
\hline $\mathrm{Cz}$ & $7.83 \pm 6.38$ & $10.54 \pm 6.39$ & & \\
\hline $\mathrm{Pz}$ & $5.49 \pm 5.84$ & $5.58 \pm 5.69$ & & \\
\hline $\mathrm{C} 3$ & $7.91 \pm 6.37$ & $9.91 \pm 5.90$ & & \\
\hline $\mathrm{C} 4$ & $6.98 \pm 6.45$ & $9.27 \pm 6.07$ & & \\
\hline Fp1 & $11.59 \pm 8.54$ & $10.55 \pm 8.09$ & & \\
\hline F3 & $7.77 \pm 8.01$ & $10.13 \pm 8.09$ & & \\
\hline F4 & $9.12 \pm 8.54$ & $8.68 \pm 7.64$ & & \\
\hline
\end{tabular}

chotic symptoms. Among those who had psychotic symptoms, 9 had concomitant manic/mixed episode and 1 had depressive episode. The average number of hospitalizations was 0.46 times $(\mathrm{SD}=0.50)$. The patient group had a mean YMRS score of $0.96(\mathrm{SD}=0.80)$ and HDRS score of $0.76(\mathrm{SD}=0.72)$ at the time of assessment. The mean duration of remission was 6.66 months $(\mathrm{SD}=7.57)$ at the time of testing. There was no significant group difference between patient and control groups in terms of education ( $p=0.323)$, family type $(p=0.602)$, family income $(\mathrm{p}=0.292)$, and residence $(\mathrm{p}=0.426)$. While $10 \mathrm{pa}-$ tients were receiving either lithium $(16.66 \% ; n=5)$ or sodium valproate (16.66\%; $n=5)$ monotherapy, 20 patients $(66.66 \%)$ had been taking combination therapy in the form of mood stabilizers and antipsychotics or $>1$ mood stabilizers.

Multivariate analysis failed to detect any main effect on $\mathrm{CNV}$ amplitude (Pillai's Trace 0.211 ) or latency (Pillai's Trace 0.111). Both groups were comparable in terms of $\mathrm{CNV}$ parameters (Table 1).

\section{DISCUSSION}

Our study of paediatric bipolar disorder patients during strict euthymic phase did not reveal any abnormality of the contingent negative variation. To the best of our knowledge, this is the first CNV study done on PBD population. Moreover, we had higher sample size, used structured interviews for diagnosing patients and also recruited a pure sample of PBD during strict euthymia. Our study design was such that would al- low us to investigate any potential 'trait marker' of this debilitating condition.

With the available limited literature on $\mathrm{CNV}$ in bipolar disorder population, we considered our negative finding as quite significant. Our finding appears to be consistent with the already existing limited literature that has failed to find $\mathrm{CNV}$ as a useful tool to investigate this condition. However, we would like to put forward several potential testable explanations to discuss this negative finding:

Firstly, PBD or Bipolar Disorder subjects as such, may not have any specific abnormality in motor preparation or anticipation of events. Impairment in anticipation of events has been documented in Schizophrenia ${ }^{15}$; therefore, this negative CNV finding, in fact, could help in differentiating between the two major psychiatric conditions.

Secondly, the neuro-anatomical substrate of the CNV waveform in Bipolar Disorder may be different. This is only a tentative hypothesis, as we could not find any specific CNV-fMRI study on BD patients. Nagai et al. ${ }^{23}$ simultaneously recorded fMRI and EEG to specifically investigate CNV related brain activities. The authors found contributions from Supplementary Motor Area, cingulate, thalamus, and bilateral insula in anticipatory attention and motor preparatory processes indexed electrophysiologically by generation of the CNV.

On the other hand, studies looking at the functional neuroanatomy of BD have consistently pointed towards altered activation of the anterior limbic network that comprises of the prefrontal cortex, anterior cingulate, amygdala, basal ganglia 
and thalamus. In fact the most consistent finding ${ }^{24}$ is the overactivation of the thalamus, amygdala and striatum.

Thirdly, it is also possible that any CNV abnormality in PBD or BD may not be state-independent and since we studied during strict euthymia, we failed to detect any significant finding. In the past, hopelessness and suicidal thoughts (affectladen thoughts) as well as psychotic symptoms such as firstrank Schneiderian symptoms (FRS) were found to be negatively correlated with CNV amplitude. ${ }^{25}$ However, such findings need replication. Ghadirian and Dubrovski ${ }^{17} \mathrm{did}$ not find any association even during symptomatic phase, although the sample size was too small.

\section{Limitation}

One potential limitation of our study was the potential confounding effect of medication on CNV parameters in the PBD population. Moreover, we also considered whether our one time case control design, very much used in the contemporary Event Related Potential research, was appropriate to investigate $\mathrm{CNV}$ in $\mathrm{BD}$ population. In the mid -70s, authors like $\mathrm{Ab}$ raham et al. ${ }^{26}$ commented that $\mathrm{CNV}$ provides an indication of enduring abnormal personality traits rather than subject's mental state at the time of testing. However, we are also aware that studies with a longitudinal design, albeit limited by small sample size, also have been inconclusive.

The other potential limitation of our study could be the choice of reference method. In our study, we chose to use linkedear reference, opposed to average reference that is known to improve signal-to-noise ratio (SNR). However, we would argue that, in our study, the use of average reference may not be an ideal choice because a) we only gathered data from 7 electrodes and b) the distribution of electrodes was uneven (mostly anterior distribution).

In summary, existing research using CNV paradigm in $\mathrm{BD}$ population remains controversial and in our study, we did not find any evidence of abnormality of the $\mathrm{CNV}$ in a pure sample of remitted paediatric bipolar patients. We propose that $\mathrm{CNV}$ is unlikely to be a true endophenotype of BD. However, absence of CNV finding during euthymic phase in BD may still help us in advancing our understanding of BD and such finding may, in fact, have some specificity with regard to differentiating BD from schizophrenia. Future research may explore this issue further.

\section{REFERENCES}

1. Walter WG, Cooper R, Aldridge VJ, McCallum WC, Winter AL. Contingent negative variation: an electrical sign of sensorimotor association and expectancy in the human brain. Nature 1964;203:380-384.

2. Skinner JE. Brain Control of Cardiovascular Dynamics. In: Brunia CH, Mulder G, Verbaten MN, Editors. Event-Related Brain Research- Electroencephalography and Clinical Neurophysiology. Amsterdam: Else- vier, 1991, p.270-283.

3. Tecce JJ. Contingent negative variation $(\mathrm{CNV})$ and psychological processes in man. Psychol Bull 1972;77:73-108.

4. Lolas F, de Andraca I. Neuroticism, extraversion and slow brain potentials. Neuropsychobiology 1977;3:12-22.

5. Wilkinson RT, Seales DM. EEG event related potentials and signal detection. Biol Psychol 1978;7:13-28.

6. Brunia CH, Van Boxtel GJ. Wait and see. Int J Psychophysiol 2001;43: 59-75.

7. Ruchkin DS, Canoune HL, Johnson R Jr, Ritter W. Working memory and preparation elicit different patterns of slow wave event-related brain potentials. Psychophysiology 1995;32:399-410.

8. Clark L, Iversen SD, Goodwin GM. Sustained attention deficits in bipolar disorder. Br J Psychiatry 2002;180:313-319.

9. Harmer CJ, Clark L, Grayson L, Goodwin GM. Sustained attention deficit in bipolar disorder is not working memory impairment in disguise. Neuropsychologia 2002;40:1586-1590.

10. Dickstein DP, Treland JE, Snow J, McClure EB, Mehta MS, Towbin KE, Pine DS, et al. Neuropsychological performance in paediatric bipolar disorder. Biol Psychiatry 2004;55:32-39.

11. Doyle AE, Wilens TE, Kwon A, Seidman LJ, Faraone SV, Fried R, et al. Neuropsychological functioning in youth with bipolar disorder. Biol Psychiatry 2005;58:540-548.

12. Pavuluri MN, Schenkel MA, Aryal S, Harral EM, Hill SK, Herbener ES, et al. Neurocognitive function in unmedicated manic and medicated euthymic paediatric bipolar patients. Am J Psychiatry 2006;163:286-293.

13. Karayanidis F, Nicholson R, Schall U, Meem L, Fulham R, Michie PT. Switching between univalent task-sets in schizophrenia: ERP evidence of an anticipatory task-set reconfiguration deficit. Clinical Neurophysiol 2006;117:2172-2190.

14. Klein C, Heinks T, Andresen B, Berg P, Moritz S. Impaired modulation of the saccadic contingent variation preceding antisaccades in scihzophrenia. Biol Psychiatry 2000;47:978-990.

15. Wynn JK, Horan WP, Kring AM, Simons RF, Green MF. Impaired anticipatory event-related potentials in schizophrenia. Int J Psychophysiol 2010;77:141-149.

16. Rizzo PA, Amabile G, Caporali M, Pierelli F, Spadaro M, Zanasi M, et al. A longitudinal CNV study in a group of five bipolar cyclothymic patients. Biol Psychiatry 1979;14:581-586.

17. Ghadirian AM, Dubrovsky B. A longitudinal CNV study of the evolution and treatment of bipolar illness. Int J Neurosci 1993;72:245-250.

18. American Psychiatric Association. Diagnostic and Statistical Manual of Mental Disorders (DSM-IV), 4th Edition. Washington DC: American Psychiatric Association; 1994.

19. Shamsunder C, Sriram TG, Muraliraj SG, Shanmugham V. Validity of a short 5-item version of the general health questionnaire. Indian J Psychiatry 1986;28:217-219.

20. Kaufman J, Birmaher B, Brent D, Rao U, Flynn C, Moreci P, et al. Schedule for Affective Disorders and Schizophrenia for School Age Children -Present and Lifetime Version (K-SADS-PL): initial reliability and validity data. J Am Acad Child Adolesc Psychiatry 1997;36:980-988.

21. Young RC, Biggs JT, Ziegler VE, Meyer DA. A rating scale for mania: reliability, validity and sensibility. Br J Psychiatry 1978;113:429-435.

22. Hamilton M. A rating scale for depression. J Neurol Neurosurg Psychiatry 1960;23:56-62.

23. Nagai Y, Critchley HD, Featherstone E, Fenwick PB, Trimble MR, Dolan RJ. Brain activity relating to the contingent negative variation: an fMRI investigation. NeuroImage 2004;21:1232-1241.

24. Cerullo MA, Adler CM, Delbello MP, Strakowski SM. The functional neuroanatomy of bipolar disorder. Int Rev Psychiatry 2009;21:314-322.

25. Bachneff SA, Engelsmann F. Correlates of cerebral event-related slow potentials and psychopathology. Psychol Med 1983;13:763-770.

26. Abraham P, McCallum WC, Gourlay J. The CNV and Its Relation to Specific Psychiatric Syndromes. In: McCallum WC, Knott JR, Editors. The Responsive Brain. Bristol: John Wright, 1976, p.144-149. 